\title{
Are Road Transportation Investments in Line with Demand Projections? A Gravity-Based Analysis for Turkey
}

\author{
Füsun Ülengin ${ }^{a}$, Özay Özaydın ${ }^{b}$, Burç Ülengin ${ }^{c}$, Andreas Kopp ${ }^{d}$, Şule Önsel ${ }^{b}$, Özgür Kabak ${ }^{\mathrm{e}}$ \\ Emel Aktaş ${ }^{\mathrm{f}}$
}

\footnotetext{
${ }^{a}$ Corresponding author, Dogus University, Department of Industrial Engineering, Acibadem, Zeamet Street No. 21, Kadikoy, 34722 Istanbul, Turkey fulengin@ dogus.edu.tr , Tel.: +90 532595 3903; fax: +90 2163279631.

${ }^{\mathrm{b}}$ Dogus University, Department of Industrial Engineering, Acibadem, Zeamet Street No. 21, Kadikoy, 34722 Istanbul, Turkey oozaydin@ dogus.edu.tr, sonsel@ dogus.edu.tr

${ }^{\mathrm{c}}$ Istanbul Technical University, Management Engineering Department, Macka, 34367 Istanbul, Turkey, ulenginbur@itu.edu.tr

${ }^{\mathrm{d}}$ The World Bank, 1818 H Street, NW, Washington, DC 20433 USA akopp@ worldbank.org

${ }^{\mathrm{e}}$ Istanbul Technical University, Industrial Engineering Department, Macka, 34367 Istanbul, Turkey, kabak@itu.edu.tr

${ }^{\mathrm{f}}$ Business School, Brunel University, Kingston Lane, Uxbridge, UB8 3PH, UK, emel.aktas@brunel.ac.uk
}

\begin{abstract}
In this research, an integrated gravity-based model was built, and a scenario analysis was conducted to project the demand levels for routes related to the highway projects suggested in TINA-Turkey. The gravity-based model was used to perform a disaggregated analysis to estimate the demand levels that will occur on the routes which are planned to be improved in specific regions of Turkey from now until 2020. During the scenario development phase for these gravity-based models, the growth rate of Turkey's GDP, as estimated by the World Bank from now until 2017, was used as the baseline scenario. Besides, it is assumed that the gross value added (GVA) of the origin and destination regions of the selected routes will show a pattern similar to GDP growth rates. Based on the estimated GDP values, and the projected GVA growth rates, the demand for each selected route was projected and found that the demand level for some of these road projects is expected to be very low, and hence additional measures would be needed to make these investments worthwhile.
\end{abstract}

Keywords: Gravity-based model, scenario analysis, transport demand forecast, Turkey

\section{Introduction}

Since the 2001 White Paper on Transport (ETP, 2000), countries of the European Union have made significant progress in alleviating the problem of imbalance among transportation-mode uses. Further market development has taken place in aviation, road travel, and to some extent in rail transportation. The Single European Sky initiative has been successfully launched. The safety and security of transportation across all modes has increased. New rules on working conditions and on passenger rights have been adopted. Trans-European transportation networks (financed through TEN-T, Structural Funds, and the Cohesion Fund) have contributed to territorial cohesion and the building of high-speed railway lines. International ties and cooperation have been strengthened. Much has also been done to enhance the environmental performance of transportation activities.

However, the dominance of highway transportation still continues. In 2007, the percentages of traffic in the EU-25 countries are $84.9 \%$ and $43.5 \%$ for highway passenger transportation 
and highway freight transportation respectively (Transport Operational Program (TOP), 2007).

The White Paper published in 2011 (ETP, 2011) emphasizes that the transportation system is still not sustainable. If the oil dependence of transportation activities were slightly below $90 \%$, with renewable energy sources only marginally exceeding the $10 \%$ target set for 2020 , $\mathrm{CO}_{2}$ emissions from transportation would still reach a level one-third higher than their 1990 level by 2050. Congestion costs would increase by approximately 50\% from now until 2050 .

Similar trends in the imbalance in transportation-mode usage can also be seen in Turkey in an even more dramatic way. Unfortunately, the Turkish transportation network has not followed a planned growth strategy. The share of highway travel as a percentage of total traffic has reached $92 \%$ for freight transportation and $95 \%$ for passenger transportation. In the Seventh Five-Year Plan 1996-2001 (State Planning Organization (SPO), 1996), an average increase of $10.9 \%$ in freight transportation by rail was recommended. However, between 1995 and 1998, rail freight transportation in fact decreased by $0.4 \%$ per year, and while the share of railways in total freight transportation was $2.3 \%$ in 1995 , it declined to $2.1 \%$ in 1999 . There was no Transportation Master Plan which aimed to integrate the various transportation modes to provide a balanced multimodal system. The Eighth Five-Year Plan 2001-2006 (SPO, 2001) proposed the development of a Transportation Master Plan to overcome all these problems.

The Ninth Development Plan (2007-2013) (SPO, 2007) is the major policy document of Turkey which sets out the priorities of the country in economic, social, and cultural fields. The Plan underlines the fact that the share of highway transportation in freight transportation nationwide increased from $88.7 \%$ in 2000 to $90 \%$ in 2005 . The share of maritime transportation, which had long been small, decreased even further to $2.8 \%$ in 2005 . Railways and pipeline transportation maintained their percentages. During the period of the eighth fiveyear plan, $95.2 \%$ of passenger transportation nationwide was achieved by highway. According to 2005 statistics, in Turkey, 95\% of passengers were carried by road and only $2.6 \%$ by rail. On the other hand, $91 \%$ of freight was carried by road, $5 \%$ by rail, and $3 \%$ by water (TOP, 2007). In international freight transportation, the shipping lines (86\%), and in international passenger transportation, the airways conserved their dominant positions. Despite the fact that shipping lines are dominant in foreign freight transportation, their share of total transportation was low because they constituted a very low share of domestic transportation.

In Turkey, the current railway network is $10,984 \mathrm{~km}$, of which $8,687 \mathrm{~km}$ are main lines. Turkey lags behind the EU countries in terms of railway infrastructure and transportation. The most important problem is the insufficiency of railway lines in terms of speed and service quality. Turkey is also below the EU average in total railway traffic. The low levels of investment in railway and port infrastructure and the lack of a sound strategic development framework have led to the unequal growth of various transportation modes. Therefore, the fundamental problem underlying the current situation has arisen from the past policies which mainly disregarded rail and port infrastructure while focusing on roads to ensure a higher level of accessibility within the country (TOP, 2007)

Current Turkish transportation policy, as articulated in such major policy documents as the Eighth (SPO, 2001) and Ninth Development Plans (SPO, 2007), the Transport Master Plan Strategy (2005), the Strategic Coherence Framework, and in studies like TINA-Turkey (Mueller, 2007), now focuses on alleviating the imbalance among the various transportation modes by placing more emphasis on railway and port investments (TOP, 2007). 
In Turkey, ministries and transport agencies have responded with ambitious expansion plans for transport infrastructure. The railways have set ambitious targets to increase their share of land transportation to 10 per cent of passenger and 15 per cent of freight transportation. However, contrary to these expectations, there are other plans which aim to expand the highway system significantly. It is evident that if the necessary investment is not undertaken immediately to shift passenger demand towards rail transportation, the modal imbalance will become worse as the bias towards highway transportation continues to increase. To meet these targets, rail infrastructure will have to be expanded as well. Airport and port authorities will have to accommodate surges in the flows of goods and services. The main theme of the national policy of Turkey is to create a balanced, rational, and efficient structure in which transportation modes will be optimized within an overall integrated model (TOP, 2007).

In 2007, a project called TINA-Turkey (Mueller, 2007) was undertaken by international experts with the objective of developing a multimodal transport network within the Republic of Turkey and of extending the European Union's TEN-T into Turkey. The project consists of defining and assessing the multimodal transportation network in Turkey, including roads, railway lines, seaport, and airports and is divided into three main activities. The first is the development of a traffic forecasting model and the projection of traffic flows for 2020. The second consists of defining and analyzing the multimodal network and then prioritizing potential network improvement projects by means of multi-criteria analysis. The third task is the development of a common database using GIS technologies.

The final report identified core network segments and nodes where the proposed investment projects will be insufficient to meet traffic demand. Improvement projects proposed for the core network in Turkey were prioritized using a multi-criteria analysis method. However, in TINA, emphasis was placed on identifying investment needs, without focusing much on demand. Given the differences among the scenarios, the question is whether the envisaged investment levels are compatible with reasonable levels of capacity utilization or there is a mismatch between supply and demand.

Motivated by this fundamental question of whether investment is in line with the demand projections, the objective of this study is to identify whether the road-capacity expansion plans outlined in the TINA-Turkey report will be in line with the likely progress of related freight and passenger transportation demand. That is why the demand analysis conducted in this research has provided expected trends in demand drivers. For this purpose, a gravitybased model is proposed to forecast demand for 13 highway projects that are given high and medium priority in the TINA-Turkey report. This paper summarizes one module of a research project (Ülengin et al., 2011) sponsored by the World Bank.

The paper is organized as follows. In the second section, a literature review on transportationdemand projections is provided. Subsequently, disaggregated demand projections based on a gravity-based analysis conducted for the road investment projects given medium and high priority by TINA-Turkey are provided, and scenario analyses are performed. Finally, conclusions are presented and suggestions for future research are highlighted.

\section{State of the Art in Transportation-Demand Projection}

Transportation-demand modeling activity has increased considerably since the late 1970s. This has occurred mainly because of developments in the field of discrete-choice modeling and the availability of better microeconomic data sets. Understanding and predicting traveler behavior is a complex activity requiring advanced tools. 
Conventional models for transportation-mode demand are based on the maximization of a random utility function, which is the basis of discrete-choice modeling (Ben Akiva and Lerman, 1985; Cascetta, 2001). For example, Rich et al. (2009) presented a freight demand model for the choice of mode and crossing point in the Oresund region. The model was formulated as a weighted discrete-choice model. Wardman (2006) estimated an enhanced model to forecast railway demand and to explain the high levels of growth in the 1990s in Great Britain. GDP was found to be the key demand driver, but other variables such as variations in car travel times, fuel costs, car ownership levels, population growth, and a postprivatization time trend also played a role. The estimated models were able to predict rail growth successfully over the time interval studied.

In the literature, discrete-choice models are generally used to investigate which transportation mode will be selected for a specific journey. This information is usually gathered through surveys conducted with travelers to investigate their selection of a specific mode for a specific origin-destination (O-D) pair. Therefore, the resulting model is a micro econometric model. In transportation-mode selection for a specific O-D pair, data for travel time and cost as well as the demographic and socioeconomic characteristics of the people surveyed must be available. In particular cases, even the environmental impacts of particular transportation modes can be revealed. Then the discrete-choice model based on these data can forecast and test how and in which way travel time and cost as well as passenger characteristics will influence the selection of particular transportation modes.

Demand forecasts are generally used to predict the travel behavior of potential freight shippers and passengers. Accurate forecasts are of major importance for investment decisions. An important element in forecasting is estimation of freight and passenger volumes. The objective is to predict the number of expected freight shipments and passengers traveling between two cities during a given time interval. Based on such forecasts, it may be possible to make accurate decisions about investments in different transportation modes. For example, Marin (2003) estimated the demand based on a Logit model taking into consideration the initial demand multiplied by the ratio of generalized time raised to the power of elasticity coefficients.

Various techniques exist for demand estimation; one of the most widely used is the gravitybased model (Grosche et al., 2007). Newton defined the law of gravitation in the $17^{\text {th }}$ century by stating that two celestial bodies or planets were subjected to an attraction force that depended positively on the product of their masses and negatively on their distance. This law can be applied to social phenomena of a quite different nature, but having the common characteristic of involving transfers or flows between two or more entities or sources (Filippini and Molini, 2003). It is necessary to underline that the concepts of distance and mass must be reinterpreted according to the social and economic phenomena under study.

Some of the recent studies underline that distance is not an appropriate measure of transport costs and mention that neglecting the role of time costs associated with distance may produce incorrect estimate of the elasticity of trade with respect to transport costs. For example Liu and Xin (2011) use a numerical model that incorporates time cost into the analysis of the impact of transportation uncertainty on trade flows.

The main advantage of disaggregated models is that their econometric specification can be directly obtained from microeconomic consumer theory. Moreover, they enable an accurate definition of the variables at an individual level, which makes it possible to draw precise policy conclusions. The exogenous variables used normally exhibit large variability, thereby enabling more precise estimation of the model coefficients. 
However, in many national transportation demand forecasts, the basic strategy is "predict and provide" (Schafer \& Victor, 2000). However the assumption underlying this strategy is that the future will be similar to the past. This approach cannot provide a useful guide to the EU in its attempt to adopt measures leading toward a balanced multimodal system. In accordance with the EU policies, the British Government issued a white paper on its future transportation strategy (DETR, 1998), which proposed abandoning the "predict and provide" strategy in favor of "pragmatic multi-modalism," a more integrated transport system which will be better suited to tackle the problems of congestion and pollution.

Long-range predictions of passenger and freight demand are of critical importance for planning long-lived transportation infrastructures and for assessing the consequences of future demand to guide transportation planners in the specification of policies and to avoid undesirable growth of any particular transportation mode. Such long-range predictions require large-scale, long-term models of the transportation system, but that pressing need is in sharp contrast with the limited capabilities of existing, traditional forecasting and modeling techniques. These multivariate methods deteriorate rapidly as their projections extend farther into the future. It is well known that "qualitative" or "technological" approaches to forecasting techniques are more suitable for long-term prediction. In the short term, the assumption that the future will be similar to the past can be more easily defended. However, when the period of analysis is the medium or long term, it becomes very difficult to accept this principle.

Quantitative forecasting techniques analyze past data and make forecasts based on the relationships between variables according to these data. In technological forecasts, however, past data remain important, but the opinions and speculations of experts also play a crucial role. In the EU countries, with a wide spectrum of critical issues encountered in their transportation sectors, several scenario-based analyses have been conducted, such as integrated transportation forecasting, estimated profitability of high-speed train usage, and highway freight projections. The database and scenarios in a strategic transportation report are a good reference for the variables and databases used to investigate the long-term transportation-demand predictions and related scenarios in different EU countries. Generally, those variables are grouped into categories such as "socio-economic data," "transportation economic data," "energy data," "foreign trade data," "environment data," "transportationmode price data", and "accident data" (Transportation Research: APAS, 1999). As can be seen in the referenced EU publication, in almost all of the scenarios that have been developed to forecast transportation demand in EU countries, the "gross national product" is the basic variable included in the model. The main reason for this is the high level of correlation between gross national product and transportation demand. Export, import, and employment variables are next in importance. Inclusion of other variables in the models depends on the nature of the research and the level of detail requested.

Ülengin et al. (2007) proposed an integrated transportation decision-support system (TDSS) to enable the formulation of aggregate long-term scenarios (countrywide, regional, or global). This research was an important part of the report prepared for the Ministry of Transportation in preparation of the Transportation Master Plan Strategy (2005). The proposed model did not require detailed data such as trip lengths and O-D matrices, but rather used aggregate data to make projections of passenger and freight transportation demand for each transportation mode in the future. The first step of the proposed TDSS was the development of a belief net representing the transportation system under analysis. For this purpose, the relevant variables in the system were initially determined through a study of the literature and the variable specifications used in similar studies, which were then revised according to experts' 
judgments. In the next stage, the causal relationships between the variables were determined through integration of the results using traditional econometric techniques, strengths of relationships obtained from artificial neural networks, and finally revisions based on the subjective judgments of experts. Subsequently, the static causal model was transformed into a dynamic model through a Bayesian causal map (BCM). The resulting map was used for scenario analysis to help transportation planners support policymakers in their analysis of the impact of socioeconomic variables and transportation-related variables on future passenger and freight transportation demand. However, this research is based on aggregate data and therefore does not provide useful information about whether a specific transportation investment project is in line with its demand or not.

Therefore, in this research, an integrated gravity-based model was constructed and a scenario analysis was conducted to project demand levels for routes related to the highway projects suggested in the TINA-Turkey report.

\section{Gravity-Based Analysis of Selected Road Transportation Routes}

To assess the possibility of reaching the targets specified by policy makers for the expansion of transportation models, a gravity-based analysis was conducted. Derivations of the gravity model were heavily empirical until 1960s but then with the development of the theory, rigorous derivations of the gravity model based on optimization theory and statistical mechanics became possible (Erlander \& Stewart, 1990). Generally, the literature on gravitybased models is based on a cross-sectional methodology. In this research, however, to provide guidance on the coordination of different transportation modes while ensuring adequate investment in intermodal facilities by avoiding competing mono-modal expansion plans, the gravity-based analysis was used to perform a disaggregated analysis to estimate the level of demand that will occur on the routes scheduled for improvement in specific regions of Turkey from now until 2020.

According to the gravity-based model, the flow between any two points increases in direct proportion to the population or the economic activity level at and between these points and in inverse proportion to the distance between the points. Either the distance can be directly incorporated into the model, or other factors such as travel time or cost can be included as repelling factors. Especially if the model is designed to explain preferences among modes, even if the distance $(\mathrm{km})$ is the same, the travel time and cost of the different modes available between any two specific points will influence the preference. Reynolds et al. (2007) used a generalized cost term in the gravity model which represented inclusion of the effect of fares, travel time, and flight delay. Other variables such as trip comfort will also have an impact. However, for most of the highway projects investigated in this research, alternative transportation modes are either nonexistent or very limited. This is why the probability that repelling factors other than distance will have an impact is low. On the other hand, some of the routes in the projects investigated connect directly with a border. Therefore, information about the destination point in Turkey is not the only factor directly influencing the ton-km and passenger-km data. Some of the routes are on corridors where external trade with Iran and Iraq is conducted. Hence, the external trade of Turkey with these countries should also be taken into account. Because external trade with Syria is in a poor state, and because the 20102011 period when this trade showed a tendency to increase is not included in the data set used in this study, the variable relating to the external trade with Syria was excluded. Finally, external trade with Europe is also excluded from the analysis because this trade flows mainly through Thrace, which was not included in the set of routes selected for this research. 
In the model, the origin and destination points were selected, not as cities, but rather as regions, as described by the Turkish Statistical Institute (TUIK). Figure 1 illustrates the TUIK regions of Turkey. This is due to the fact that origin and destination points analyzed in this research are not generally cities, but rather route networks within a region. Moreover, all the selected routes are described as "upgrading/second stage" in the TINA-Turkey report (Mueller, 2007).

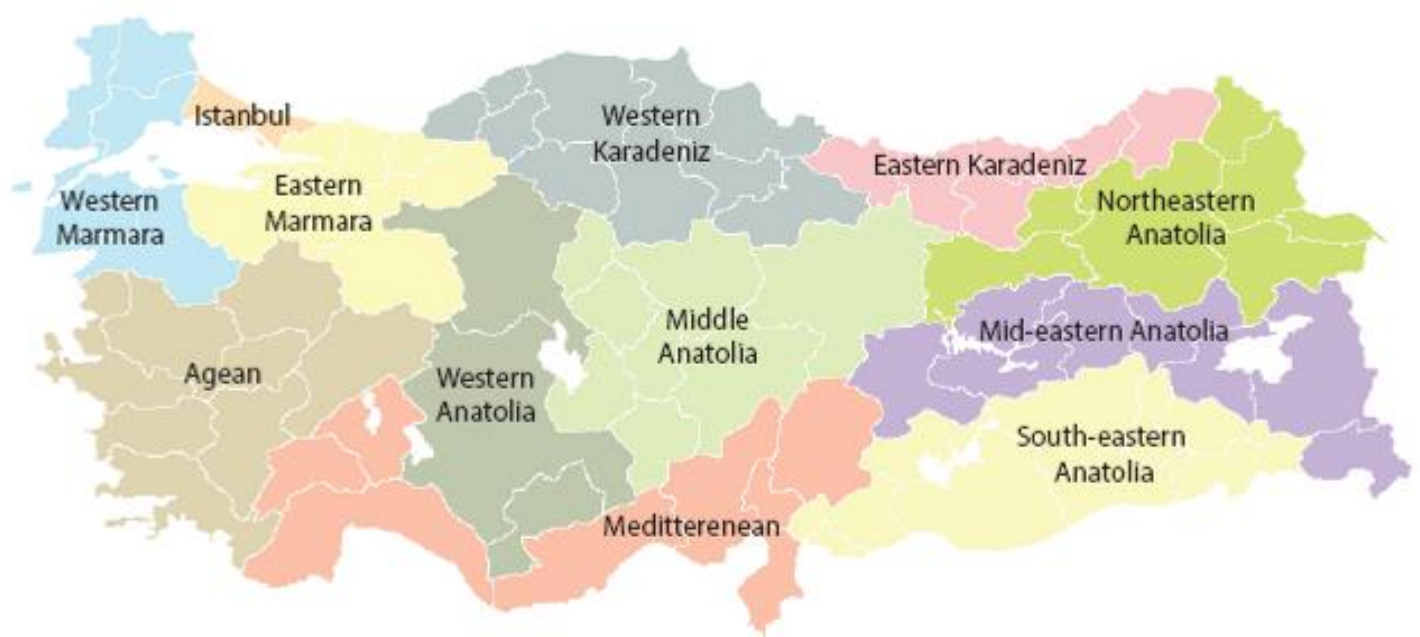

Figure 1. TUIK regions used in the analyses.

The aim is to reach an understanding of the degree of realism of the plans to perform a massive expansion of the highway infrastructure. The gravity-based analysis makes it possible to see the effects of region-specific characteristics on the demand level of the planned projects and provides a guide for creating adequate capacity and reducing congestion costs due to bottlenecks. Consequently, it will be possible to generate correct signals for distributing transportation investment across different modes according to their relative internal and external costs.

It is necessary to underline that some of the projects mentioned should have been completed in 2011 according to the TINA-Turkey report. However, it was decided to consider all of the projects for the feasibility investigation. Thirteen projects were therefore evaluated. The names of the projects cannot be provided due to privacy reasons. Instead the project numbers are given in Table 1.

Table 1. Road projects analyzed in the study (Mueller, 2007).

\begin{tabular}{|c|c|c|c|c|c|c|c|}
\hline ID & Project Type & Project no. & Priority & ID & Project Type & Project no. & Priority \\
\hline 1 & Upgrading/second stage & Project 20 & Medium & 8 & Upgrading/second stage & Project 29 & Medium \\
\hline 2 & Upgrading/second stage & Project 21 & Medium & 9 & Upgrading/second stage & Project 30 & Medium \\
\hline 3 & Upgrading/second stage & Project 22 & Medium & 10 & Upgrading/second stage & Project 31 & High \\
\hline 4 & Upgrading/second stage & Project 23 & High & 11 & Upgrading/second stage & Project 32 & High \\
\hline 5 & Upgrading/second stage & Project 24 & High & 12 & Upgrading/second stage & Project 33 & Medium \\
\hline 6 & Upgrading/second stage & Project 25 & Medium & 13 & Upgrading/second stage & Project 34 & High \\
\hline 7 & Upgrading/second stage & Project 26 & High & & & & \\
\hline
\end{tabular}

The estimates of passenger demand (in passenger-km) and freight demand (in ton-km) of each project in Table 1 were based on transportation network characteristics, represented by the 
length and the average speed of different links, as well as the flow volume for different types of vehicles (such as passenger cars, buses, trucks) on various links between 2004 and 2009 as provided by General Directorate of Highways, Republic of Turkey (KGM). In addition, for each region related to the projects that are investigated, information on the gross value added (GVA) by region was also available and included in the models.

\subsection{Methodology}

In general, aggregate and disaggregate models are of similar structure; however, required data sets and the methods for model parameter estimation are considerably different. The models to be estimated for Turkey were developed to explain transportation movements and especially were used in the forecasts of the future demand for the purposes of investment planning. In Turkey, not only the access to data required for estimating disaggregate models is limited; but also there is no data on intercity transportation. Moreover, collection of such data is not planned within the scope of this study. Therefore, a modeling approach based on an aggregate gravity model is pursued.

The general formulation of the gravity-based model developed in this research is given in Eq. (1):

$$
Q_{i j}=Y_{i} Y_{j} / d_{i j}
$$

where $Q_{i j}$ is the flow between origin $i$ and destination $j, Y_{i}$ and $Y_{j}$ are the population and/or economic activity at origin $i$ and destination $j$ respectively, and $d_{i j}$ is the distance between origin $i$ and destination $j$.

Based on the general approach described above, a model was developed to explain the freight demand in ton- $\mathrm{km}$ and the passenger demand in passenger-km for each route, as given in Eqs. (2) and (3) respectively:

$$
\begin{aligned}
& T_{K M_{i j t}}=\left(Y_{i t} \cdot Y_{j t} \cdot P O P_{i t} \cdot P O P_{j t}\right) / d_{i j} \\
& P K M_{i j t}=\left(Y_{i t} \cdot Y_{j t} \cdot P O P_{i t} \cdot P O P_{j t}\right) / d_{i j}
\end{aligned}
$$

where $Y_{i t}$ is the level of economic activity of the region encompassing origin $i$ in year $t, Y_{j t}$ is the level of economic activity of the region encompassing destination $j$ in year $t$, and $d_{i j}$ is the distance between $i$ and $j$. Definitions of other variables are given in Table 2 .

Table 2. Variable definitions.

\section{Variable Definition}

i Index for origins (12 regions given in Figure 1)

$j \quad$ Index for destinations (12 regions given in Figure 1)

$y \quad$ Index for years

$k \quad$ Index for segments of the route between origin $i$ and destination $j$

$D I S T_{k} \quad$ Length of segment $k$

$T K M_{i j t} \quad$ Freight flow in ton-km between origin $i$ and destination $j$ in year $t$

$P K M_{i j t} \quad$ Passenger flow in passenger-km between origin $i$ and destination $j$ in year $t$

$G V A_{i t} \quad$ Gross value added of the region encompassing origin $i$ in year $t$

$G V A_{j t} \quad$ Gross Value added of the region encompassing destination $j$ in year $t$

$P O P_{i t} \quad$ Population of the region encompassing origin $i$ in year $t$ 


\begin{tabular}{|c|c|}
\hline$P O P_{j t}$ & Population of the region encompassing destination $j$ in year $t$ \\
\hline$D I S T_{i j}$ & Distance between origin $i$ and destination $j$ \\
\hline $\operatorname{IRAN}_{i j t}$ & $\begin{array}{l}\text { Sum of exports and imports between Turkey and Iran (if there is a connection } \\
\text { to the Iran border through origin } i \text { and destination } j \text { ), } 0 \text { otherwise }\end{array}$ \\
\hline$I R A K_{i j t}$ & $\begin{array}{l}\text { Sum of exports and imports between Turkey and Iraq (if there is a connection } \\
\text { to the Iraq border through origin } i \text { and destination } j \text { ), } 0 \text { otherwise }\end{array}$ \\
\hline$R A$ & Average railway cost $/ \mathrm{km}$ in year $t$ \\
\hline PET & Average domestic gasoline price in year $t$ \\
\hline
\end{tabular}

In the models, the freight and passenger volume of each route segment were calculated as functions of the length of the segment to obtain the related estimates of ton-km (TKM) and passenger-km $(P K M)$ values. This is why, the longer the route investigated was, the larger were its related TKM and $P K M$ values. To eliminate this drawback, the TKM and $P K M$ variables were divided by the length of the route. $T K M_{i j}$ was calculated based on the amount of freight transported between $i$ and $j$, which was based on information concerning the segments between these two points. The amount of freight transported on each segment was multiplied by the length of the segment, and these values were then summed for all segments to determine the flow between $i$ and $j$. As a result, if the route between $i$ and $j$ was composed of $n$ segments where $D I S T_{k}$ was the length of segment $k$ and Freight $_{k}$ was the amount of freight transported in segment $k$, then $T K M_{i j}$ was calculated as follows:

$$
\operatorname{TKM}_{i j}=\sum_{k=1}^{n} \text { DIST }_{k} \cdot \text { Freight }_{k} .
$$

In that case, the total distance between $i$ and $j$ would be $D I S T_{i j}=\sum_{k=1}^{n} D I S T_{k}$. This is why, in Equations 2 and 3,TKM $M_{i j t}$ and $P K M_{i j t}$ are replaced by $T K M_{i j t} / D I S T_{i j}$ and $P K M_{i j t} / D I S T_{i j}$ respectively, which have been transformed to average ton-km and passenger-km between $i$ and $j$ in Eqs 5 and 6, as follows:

$$
\begin{aligned}
& T_{K M_{i j t}} / D I S T_{i j}=Y_{i t} \cdot Y_{j t} \cdot P O P_{i t} \cdot P O P_{j t} \\
& P K M_{i j t} / D I S T_{i j}=Y_{i t} \cdot Y_{j t} \cdot P O P_{i t} \cdot P O P_{j t}
\end{aligned}
$$

In addition to these basic variables, the relative cost of road transportation was also included in the model as an explanatory variable. The gravity model with a single generalized logistics cost function can be applied to determine the trade flows between world regions. Sea and air transportation offerings provided as an alternative to highway transportation are very limited. Because the railways may provide an alternative, especially for freight transportation, an attempt was made to use the ratio of railway cost to highway cost as an explanatory variable. However, it was not possible to obtain freight and passenger transportation price data for railways. Therefore, the average railway cost was used instead of the railway transportation price and the domestic gasoline price was used instead of the highway transportation price as proxy variables. Another reason for using a general rail cost to gasoline price ratio is due to the fact that rail and truck are highly substitutable in transporting most of the freight (Zlatoper \& Austrian, 1989). Using such a ratio enabled the models to incorporate the rail-truck competition existing in freight transportation. As explained earlier, some of the routes investigated include the link to the borders with Iran and Iraq. Therefore, the trade flows with these countries also influence the flow of passenger and freight along these routes. If the $i^{\text {th }}$ route has a connection to the Iran border, the Iran variable is equal to the sum of exports and 
imports to and from Iran in the related year; otherwise, the Iran variable is zero. Similar logic is applied to the Iraq variable.

\subsection{The Data Set}

The data used in this study is a panel data comprised of the values of the variables defined in the previous section for the years between 2004 and 2009 and for the 13 routes given in Table 1. In the pretesting phase, the data of project number 29 was found to have a different structure than the remaining projects and hence was not analyzed. The data included the origins (O), destinations (D), the distance of each O-D pair, segments between these O-D pairs, and the distance of each segment. Each O-D pair constituted a route, and the route was divided into segments for analysis purposes. The passenger and freight flows on the segments were summed to calculate the flows on O-D pairs. We are not able to give the lengths of each route due to confidentiality reasons; however, for example, the route of Project 20 in Table 1 is $230 \mathrm{~km}$ long and the route of Project 21 is $262 \mathrm{~km}$ long. Overall, passenger transport volumes in 2004 were above 20 million passengers per year and the freight flow in the regions ranged between 3,000 trucks per day to 13,000 trucks per day representing approximately 70 million tons per year. The freight and passenger flow on each route and the sum of exports and imports between Irak and Iran were included in the models for each year.

Each origin and destination represented a region and the GVA of regions were included in the models as indicators of regional economic activity; so, each origin and destination had a GVA figure for each year. In addition to GVA, population figure of each region for each year was considered in the analyses. Finally, as explained in Section 3.1 Methodology, average railway cost and average gasoline price in each year were also included in the data.

Equations (2) and (3) were then linearized by taking logarithms. When the initial analyses were performed, a high level of correlation was observed between the population (POP) and GVA values of the regions. In a region having a high GVA, the POP level was also high. To avoid multicollinearity in the estimates, instead of taking the GVA and POP values of each region separately, the per capita GVA (i.e., GVA/POP) was used.

Moreover, POP and GVA are trend-based variables. The estimated equation shows the longterm relationship among the variables assuming that certain conditions are satisfied. When the equations were estimated based on panel data, the error terms of the equations were found to have a heteroscedasticity problem. To eliminate the impact of heteroscedasticity on the standard error of estimation of the coefficients, White cross-sectional standard errors were used. Finally, in the model, regions having a high GVA/POP values were assumed to be "sending" regions (i.e., $i$ regions or origins), while the others were assumed to be "receiving" regions (i.e., $j$ regions or destinations). This assumption also incorporates the fact that in Turkey, the dominant flow of freight and passengers is from west to east. Taking into account that the western regions of Turkey produce $60 \%-70 \%$ of GVA and house a similar percentage of the population, this assumption seems logical. Moreover, the fact that the majority of the exports shipped by road are bound for Iran, Iraq, and other Middle Eastern countries also justifies this argument. Therefore, when the TKM and PKM values are to be estimated for a specific origin $i$ and destination $j$ using the gravity-based models developed in this study, it is necessary to take the region having the higher GVA/POP value as the $i^{\text {th }}$ (i.e., sending) region and the one having the lower GVA/POP value as the $j^{\text {th }}$ (i.e., receiving) region. 
To minimize these drawbacks, the variables were reformulated as shown in Eq. (7) and Eq. (8) (variable definitions are given in Table 2). Using per capita GVA as the indicator of economic activity:

$$
\begin{aligned}
& \operatorname{Ln}\left(T K M_{i j t} / D I S T_{i j}\right) \\
& =\beta_{0}+\beta_{1} \operatorname{Ln} \frac{G V A_{i t}}{P O P_{i t}}+\beta_{2} L n \frac{G V A_{j t}}{P O P_{j t}}+\beta_{3} L_{n} D I S T_{i j}+\beta_{4} I R A N_{i j t}+\beta_{5} I R A K_{i j t}+\beta_{6} L n \frac{R A I L E X P_{t-1}}{P E T_{t-1}}+u_{i j t} \\
& \operatorname{Ln}\left(P K M_{i j t} / D I S T_{i j}\right) \\
& =\beta_{0}+\beta_{1} \operatorname{Ln} \frac{G V A_{i t}}{P O P_{i t}}+\beta_{2} \operatorname{Ln} \frac{G V A_{j t}}{P O P_{j t}}+\beta_{3} \operatorname{LnDIST}_{i j}+\beta_{4} I R A N_{i j t}+\beta_{5} I R A K_{i j t} \\
& \quad+\beta_{6} \operatorname{Ln} \frac{R A I L E X P_{t}}{P E T_{t}}+\beta_{7}\left(\operatorname{LnPOP}_{i t}+\operatorname{LnPOP}_{j t}\right)+u_{i j t}
\end{aligned}
$$

Based on this proposed model, demands for both road freight and road passenger traffic were forecast. The reason for estimating the demand on a regional basis is the nature of the routes represented by the projects given in Table 1 and connecting the 12 regions given in Figure 1 . Passenger and freight flow figures are based on these routes and the GVA/POP of each region is an explanatory variable for the passenger and freight flows.

\subsection{Gravity-Based Analysis of Road Freight Transportation}

The results obtained based on the estimated freight transportation model are given in Table 3 . As can be seen from Eq. (7) in the TKM model, some of the variables (e.g., DIST) do not have $t$ indices. Because there was no change in the distance during the period under investigation, distance was assumed constant for a particular route. On the other hand, some other variables do not have $i$ and $j$ indices. For example, gasoline prices and average railway cost remain constant for each region. For this reason, in the panel data estimation, it was impossible to perform estimations based on this fixed effect. After the transformation performed in Eq. (7 and 8), the multicollinearity problem was alleviated. However, the heteroscedasticity problem still existed. For this reason, robust standard errors were calculated using the White correction.

\section{Table 3. Estimated ton-km results for highways.}

Dependent Variable: LOG(TKM/DIST)

Method: Panel Least Squares

Total panel (balanced) observations: 60

White cross-section standard errors \& covariance (d.f. corrected)

\begin{tabular}{lllll}
\hline \hline Variable & Coefficient & Std. Error & t-Statistic & Prob. \\
\hline \hline L & 3.243688 & 1.372721 & 2.362962 & 0.0218 \\
LOG(GVA_i/POP_i) & -0.016519 & 0.060483 & -0.273119 & 0.7858 \\
LOG(DIST) & 0.669439 & 0.068860 & 9.721696 & 0.0000 \\
IRAN & -0.110664 & 0.035059 & -3.156490 & 0.0026 \\
IRAK & 0.084290 & 0.008804 & 9.574401 & 0.0000 \\
LOG(RAILEXP(-1)/PET(-1)) & 0.131095 & 0.010686 & 12.26844 & 0.0000 \\
\hline R-squared & 0.537883 & 0.157328 & 3.418865 & 0.0012 \\
Adjusted R-squared & 0.336383 & Mean dependent var & 10.02507 \\
S.E. of regression & 0.261257 & S.D. dependent var & 0.401360 \\
Sum squared resid & 0.344970 & Akaike info criterion & 0.818560 \\
Log likelihood & 6.307217 & Schwarz criterion & 1.062901 \\
F-statistic & -17.55681 & Hannan-Quinn criter. & 0.914135 \\
Prob(F-statistic) & 4.477557 & Durbin-Watson stat & 0.316982 \\
\hline \hline
\end{tabular}


According to the results of the estimated equation given in Table 3, the economic level of the origin region does not have a significant effect on highway freight transportation between $i$ and $j$. This result is expectable given the explanation in section 3.2 for the determination of sending and receiving regions and it may also be due to the imbalance of the economic activity per population in regions (origins and destinations). However, the economic activity of the destination has a significant impact on road freight transportation between $i$ and $j$. In other words, the attractive power of the destination point results in freight flow. A $1 \%$ increase in per capita GVA of the region around the destination point results in a $0.66 \%$ increase in highway freight-km $(T K M)$. This result also conforms to the expectations since there is a flow of commodity from west to east in Turkey and the higher is the attractiveness of the region, the higher will be the freight flow to that region. In the routes connected to the Iran and Iraq borders, the trade between the respective country and Turkey has also a significant impact. An increase of 1 billion USD in trade with Iran increased the freight flow of the related routes by $8.8 \%$. This increase was $13.9 \%$ with Iraq. On the other hand, when the railway transportation cost increase was greater than the gasoline price, this effect was experienced with a one-year delay. When the distance of the route was increased, freight transportation volume was reduced.

\subsection{Gravity-Based Model Analysis of Road Passenger Transportation}

Generally, the explanatory variables that were found to be significant for freight transportation were also significant for passenger transportation. Table 4 gives the estimated passenger-km results for highways. In addition, population also had a significant effect, unlike for freight transportation. For the reasons explained for freight transportation, in the panel data estimation of passenger-km, it was not possible to perform the estimation with fixed effects.

\section{Table 4. Estimated passenger-km results for highways.}

Dependent Variable: LOG(PKM/DIST)

Method: Panel Least Squares

Cross-sections included: 12

Total panel (balanced) observations: 60

White cross-section standard errors \& covariance (d.f. corrected)

\begin{tabular}{lllll}
\hline \hline Variable & Coefficient & Std. Error & t-Statistic & Prob. \\
\hline \hline LOG(GVA_O/POP_O) & -11.63196 & 3.506083 & -3.317650 & 0.0017 \\
LOG(GVA_D/POP_D) & 0.325354 & 0.022545 & 14.43128 & 0.0000 \\
LOG(DIST) & 1.330700 & 0.065534 & 20.30543 & 0.0000 \\
IRAK & -0.125832 & 0.041101 & -3.061528 & 0.0035 \\
IRAN & 0.128219 & 0.017601 & 7.284676 & 0.0000 \\
LOG(RAILEXP(-1)/PET(-1)) & 0.058379 & 0.009442 & 6.182931 & 0.0000 \\
LOG(POP_O)+LOG(POP_D) & 1.647454 & 0.349002 & 4.720472 & 0.0000 \\
\hline R-squared & 0.157505 & 0.009961 & 15.81195 & 0.0000 \\
Adjusted R-squared & 0.802769 & Mean dependent var & 9.868322 \\
S.E. of regression & 0.776218 & S.D. dependent var & 0.482058 \\
Sum squared resid & 0.228040 & Akaike info criterion & 0.004978 \\
Log likelihood & 2.704127 & Schwarz criterion & 0.284224 \\
F-statistic & 7.850655 & Hannan-Quinn criter. & 0.114207 \\
Prob(F-statistic) & 30.23567 & Durbin-Watson stat & 0.834961 \\
\hline \hline
\end{tabular}

As can be seen from Table 4, the level of economic activity at both the origin and the destination had a significant impact on the volume of passenger transportation between $i$ and $j$. While an increase of $1 \%$ in per capita GVA at the origin resulted in an increase of $0.33 \%$ in 
passenger-km $(P K M)$, an increase of $1 \%$ in per capita GVA at the destination resulted in an increase of $1.33 \%$ in $P K M$. It can be seen that the impact of economic activity on passenger$\mathrm{km}$ was higher at the destination point. However variations in population at the origin and the destination had an equal impact on passenger transportation. An increase of $1 \%$ in population resulted in an increase of $0.16 \%$ in passenger- $\mathrm{km}$. The number of passenger-km generated by population variations was relatively much less than that generated by economic activity. The increase in trade with Iran and Iraq influenced passenger transportation on related routes in a similar way. An increase of 1 billion USD in the trade between Turkey and Iraq increased the passenger flow on related routes by $13 \%$ whereas the same figure is $5 \%$ for Iran. When the railway transportation cost increase was higher than the increase in gasoline prices, an increase in highway passenger transportation was experienced, and this increase was relatively much greater than the increase in freight transportation. However, this increase also occurred with a one-year time lag. As expected, when the distance between the origin and destination of the route was increased, passenger transportation decreased.

Since the models given in Table 3 and Table 4 will be used to forecast the following years, the forecast power of these models is expected to be high. Due to the fact that there is nine years' data for each line in the dataset, it is not possible to do the breakdown test. Therefore, the forecast ability is tested using an approach based on the Chow Forecast test (Chow, 1960). For this purpose, two dummy variables were defined for the last two years of the analysis period. $D U M_{1}$ and $D U M_{2}$ are the dummy variables for 2009 and 2008 respectively.

$$
\begin{aligned}
& \text { DUM }_{1}= \begin{cases}1 & \text { if } t=2009 \\
0 & \text { otherwise }\end{cases} \\
& \text { DUM }_{2}= \begin{cases}1 & \text { if } t=2008 \\
0 & \text { otherwise }\end{cases}
\end{aligned}
$$

The equations given in Table 3 and Table 4 were estimated after including $D U M_{1}$ and $D U M_{2}$ variables in the explanatory variables set. The significance of individual coefficient of each dummy variable was tested with the $t$-test. The joint significance of the coefficients of $D U M_{1}$ and $D U M_{2}$ variables was tested with the Wald test and the null hypothesis that the coefficients were zero was rejected. This finding is a powerful indicator to suggest the models can be used for forecasting the future demand; however, these models need to be re-estimated and tested using data of longer time periods. If disaggregate data sets are collected, then disaggregate models should be estimated and their results should be compared (Kim et al., 2009).

\section{Scenario Analysis for Disaggregated Demand Projections}

In this research, scenario analyses were also developed to provide freight and passenger demand projections for the projects of selected road routes and railway lines, as proposed in the TINA-Turkey report. The aim was to determine whether the demand for the selected projects would be sufficient to justify the investments made for this purpose. Accordingly, the following scenarios were developed concerning the GDP growth rate as estimated by the World Bank. The GVA values of the origin and destination of each route were assumed to vary in parallel with the proposed GDP growth rates (adjusted GDP values) given in Table 5. In addition to this baseline scenario, a situation (Scenario 1) was also investigated in which the eastern region of Turkey would experience faster development because of a high level of investment to be made in this area. As a result, the GVA/POP parameter of the eastern region was assumed to increase by $10 \%$ with respect to the GDP growth-rate adjusted GVA/POP, and the western region was assumed to have a $10 \%$ lower value. In Scenario 2, the reverse situation was investigated, in which the western region had higher growth and the eastern region had lower growth with the same $10 \%$ figure. In fact, transportation policymakers can 
investigate different GVA values for each region using the models estimated here, leading to different scenarios.

Table 5. GDP growth rate estimated by World Bank.

\begin{tabular}{lllllllll} 
& $\mathbf{2 0 1 0}$ & $\mathbf{2 0 1 1}$ & $\mathbf{2 0 1 2}$ & $\mathbf{2 0 1 3}$ & $\mathbf{2 0 1 4}$ & $\mathbf{2 0 1 5}$ & $\mathbf{2 0 1 6}$ & $\mathbf{2 0 1 7}$ \\
\hline Baseline - Real GDP growth rate (\%) & 8.5 & 4.5 & 5 & 5 & 5.2 & 5.3 & 5 & 5
\end{tabular}

As can be seen in Figure 2, some of the selected projects were estimated to have very low demand projections from now until 2017. For example, project ID 8 had very low demand both in current and future projections and for both passenger and freight transportation. A similar situation occurred for project ID 12. On the other hand, projects ID 9 and ID 11 had very low freight demand projections, while their passenger demand projections were at an average level. In addition, project ID 1 seemed to be a very promising investment because its demand projections for both passenger and freight were relatively high and continued to increase.

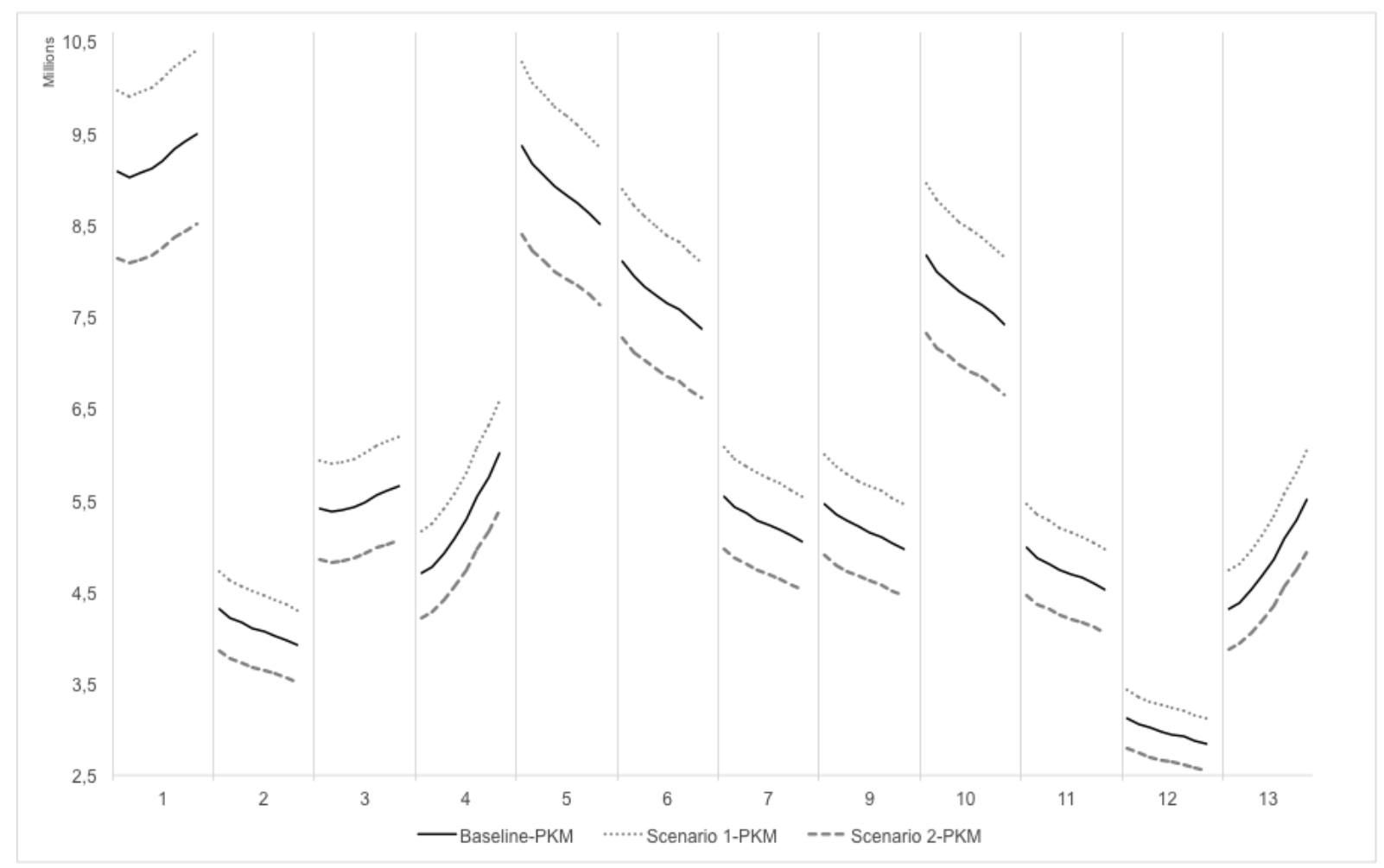

Figure 2. Passenger demand projections for selected road projects 


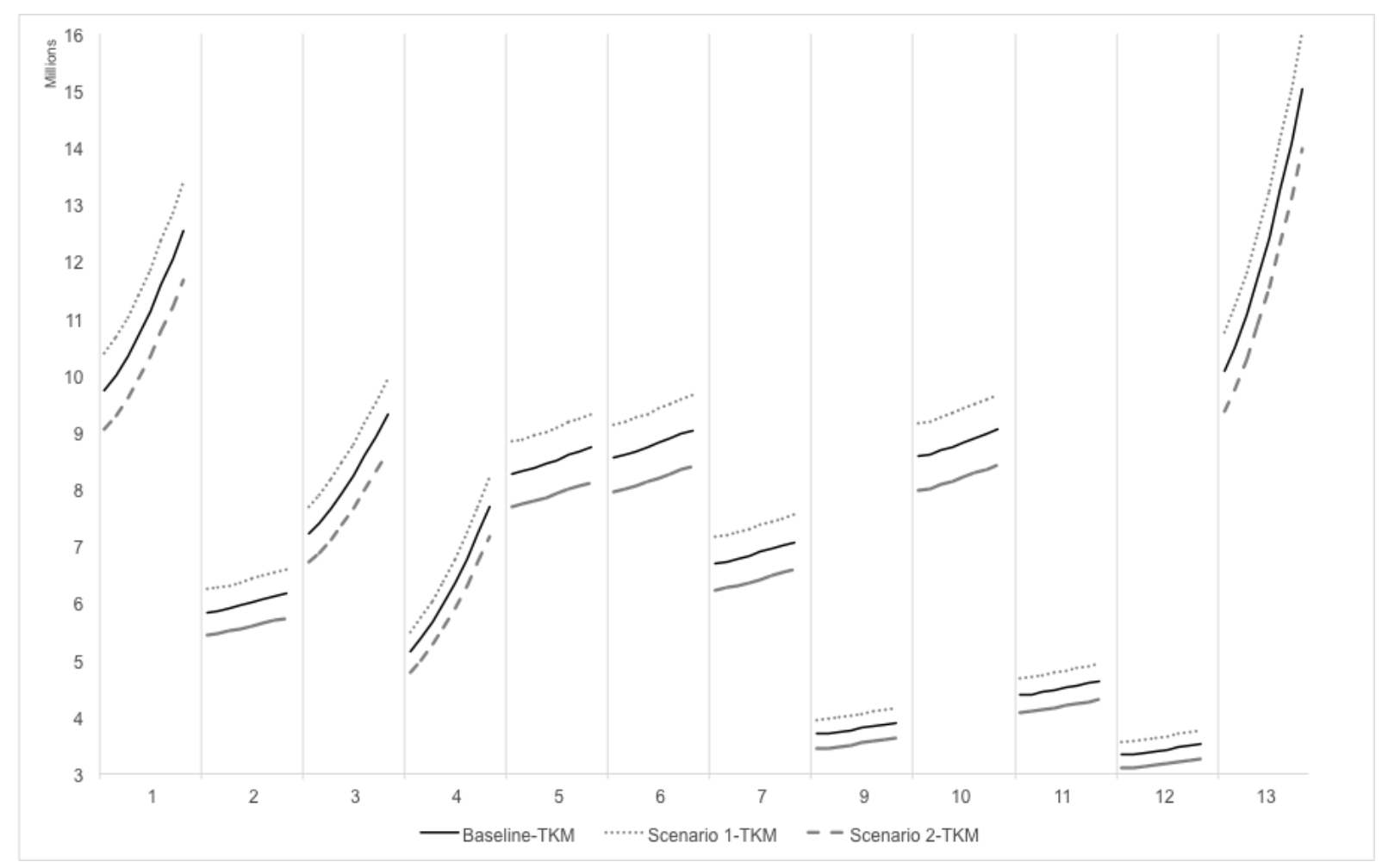

Figure 3. Freight transportation demand projections of selected road projects

If the eastern region of Turkey experienced a higher GVA/POP growth rate than the one calculated based on GDP adjusted values, demand for passenger road transportation would shift upwards (see Figure 2). However, if the western GVA/POP showed a higher growth rate, the demand for passenger road transportation would decrease by almost one million PKM.

In the scenarios developed for freight demand projections of selected road projects, the freight demand showed similar patterns to passenger demand. In other words, when the GVA/POP of the eastern regions increased at a higher rate than that calculated based on the GDP-adjusted rate, the freight demand of all the selected routes increased, while on the contrary, it decreased when the GVA/POP value of the western regions showed a relatively higher growth rate.

\section{Conclusions and Discussions}

Recently, Turkey has made substantial investments in different transportation modes to achieve a more balanced structure. As outlined in the TOP report, the investment projects that were prioritized in the TINA-Turkey report were selected as eligible for investment. In this research, a disaggregated analysis has been conducted to determine whether the freight and passenger demand projections for selected road routes are in line with the proposed transportation investments.

During the scenario development for these gravity-based models, the growth rate of GDP in Turkey as estimated by the World Bank from now until 2017 was used as the baseline scenario, with the assumption that the GVA of the origin and destination regions of the selected routes would show a pattern similar to GDP growth rate. Based on these different GDPs, and hence GVA growth rates, the demand for each selected route was projected.

Among the selected road projects, project ID 1 seems to be a very promising investment because its demand projections for both passenger and freight are relatively high and will 
continue to increase. However, based on the investigated GDP growth rate scenarios, the demand level for some of the road projects will be very low, and additional measures will be required to make these investments worthwhile. These results may be due to the assumption that the regional GVA growth rates would show a pattern similar to GDP growth rates in the projected years. This situation may change in cases where the GVA values of particular regions are higher than the average GDP growth rate in the projected years; these cases should be analyzed further by the transport planners. Similarly, the gravity-based analysis shows that the ratio of average railway cost to average gasoline price has a substantial impact on demand projections. Therefore, scenarios based on different ratios may also change this low trend in the passenger and freight demand projections for rail and road transportation.

A possible limitation of this research is that it does not take into consideration the non-linear relationship between travel intensity and distance. This could be one way to extend this research in the future.

A similar type of gravity-based analysis should also be conducted for the demand projections of the other transportation modes to determine whether investments in these modes are in line with projections and also to identify appropriate measures to ensure a more balanced transportation system.

\section{Acknowledgements}

The authors would like to express their gratitude to Mediha Ağar (World Bank) as well as Turkish State Railways, General Directorate of Highways, Turkish Airways and Turkish Maritime Lines authorities for their invaluable contribution during data acquisition as well as for their invaluable comments during the preparation of the report. Our special thanks are for İbrahim Çelik, Ömer Çevik, Yaşar Rota (Turkish State Railways) and Kemal Y1llıçıı (Turkish Airways) for their great support during the data collection phase.

\section{References}

Ben Akiva, M., Lerman, S. (1985). Discrete Choice Analysis Theory and Application to Travel Demand. MIT Press, Cambridge, MA.

Cascetta, E. (2001). Transportation Systems Engineering: Theory and Methods. Springer.

Chow, G. C. (1960). Tests of equality between sets of coefficients in two linear regressions. Econometrica, 28, 591-605.

Kim, C., Choi, C. G., Cho, S., \& Kim, D. (2009). A comparative study of aggregate and disaggregate gravity models using Seoul metropolitan subway trip data. Transportation Planning and Technology, 32(1), 59-70.

DETR: Department of the Environment, Transport, and the Regions (1998). A New Deal for Transport: Better for Everyone. Cmnd 3950, The Stationery Office, London.

Erlander, S., \& Stewart, N. F. (1990). The gravity model in transportation analysis: theory and extensions (Vol. 3). Vsp.

ETP: Environment and Transport Planning (2000). White Paper: European Transport Policy for 2010: Time to Decide. Office for Official Publications of the European Communities.

ETP: Environment and Transport Planning (2011). European Commission White Paper:

Roadmap to a Single European Transport Area: Towards a Competitive and ResourceEfficient Transport System. European Commission, Brussels. 
Filippini, C., Molini, V. (2003). The determinants of East Asian trade flows: a gravity equation approach. Journal of Asian Economics 14(5): 695-711.

Grosche, T., Rothlauf, F., Heinzl, A. (2007). Gravity models for airline passenger volume estimation. Journal of Air Transport Management 13(4): 175-183.

Liu, X., Xin, X. (2011). Transportation uncertainty and international trade. Transport Policy 18: $156-162$.

Marin, E. (2003). Demand forecast, congestion charge and economic benefit of an automated highway network for the paris agglomeration. Transport Policy 10: 107-120.

Mueller, R. (2007). Technical Assistance to Transportation Infrastructure Needs Assessment for Turkey. Final Report (TINA, Turkey) Joint Venture, 2007.

Reynolds, T., Barrett, S., Dray, L., Evans, A., Köhler, M., Vera-Morales, M., Schäfer, A.,Wadud, Z., Britter, R., Hallam, H., Hunsley, R., 2007. Modeling environmental \& economic impacts of aviation: introducing the aviation integrated modeling tool. In: Seventh AIAA Aviation Technology, Integration and Operations Conference, Belfast, 18-20 September. AIAA, Reston (VA).

Rich, J., Holmblad, P.M., Hansen, C.O. (2009). A weighted logic freight mode-choice model. Transportation Research Part E: Logistics and Transportation Review 45(6): 1006-1019.

Schafer, A., Victor, D. (2000). The future mobility of the world population. Transportation Research Part A 34: 171-205.

State Planning Organization (SPO), Republic of Turkey (1996). Seventh Five-Year Plan 1996-2000. Ankara.

State Planning Organization (SPO), Republic of Turkey (2001). Long-Term Strategy and Eight Five-Year Development Plan 2001-2005. Ankara. Available online:

http://ekutup.dpt.gov.tr/plan/viii/plan8i.pdf (23.08.2011)

State Planning Organization (SPO), Republic of Turkey (2007). Ninth Development Plan 2007-2013 (2007). Ankara. Available online:

http://ekutup.dpt.gov.tr/plan/ix/9developmentplan.pdf (23.08.2011)

Ministry of Transportation, Republic of Turkey (2005). Transportation Master Plan Strategy. Ministry of Transportation, Republic of Turkey (2007). The Transport Operational Program 2007-2009 (TOP).

Transport Research: APAS (1999). Strategic Transport Databases and Scenarios for European Transport. Luxembourg: Office for Publications of the European Commission.

Ülengin, F., Özaydın, Ö., Ülengin, B., Önsel Ş., Kabak, Ö. (2011) 'Demand Analysis for the Third Programmatic Public Expenditure and Financial Management Review, Turkey Transport Sector Expenditure Review, World Bank Synthesis Report (in press)

Ülengin, F., Onsel, S., Topcu, Y.I., Aktas, E., Kabak, O. (2007). An integrated transportation decision support system for transportation policy decisions: the case of Turkey, Transportation Research Part A 41, 80-97.

Wardman, M. (2006). Demand for rail travel and the effects of external factors. Transportation Research Part E: Logistics and Transportation Review 42(3): 129-148. 
Zlatoper, T. J., \& Austrian, Z. (1989). Freight transportation demand: A survey of recent econometric studies. Transportation, 16(1), 27-46. 